\title{
An Unusual Case of Gastric Cancer presenting with Anemia and Extensive Bone Metastases: A Rare Case Report
}

Ambikavathy Mohan, S Kumar, Bhaskaran Ashokan

\begin{abstract}
Gastric carcinoma with metastases to bone as a first feature is relatively rare. We report a case of a 22 years patient who presented with back ache, loss of appetite, anemia generalized body ache and weakness. Laboratory investigation showed pancytopenia. A bone scintigram showed extensive skeletal metastases. Upper gastrointestinal endoscopic biopsies from stomach reported as moderately differentiated adenocarcinoma of stomach. The patient received 6 cycles of chemotherapy-DCF regimen and external beam radiotherapy for bone metastases. We report this case for the unusual mode of presentation. In unresponsive anemia with skeletal metastases the possibility of gastric cancer as primary has to be considered by the treating physicians.
\end{abstract}

Keywords: Gastric carcinoma, Bone metastases, Anemia.

How to cite this article: Mohan A, Kumar S, Ashokan B. An Unusual Case of Gastric Cancer presenting with Anemia and Extensive Bone Metastases: A Rare Case Report. Euroasian J Hepato-Gastroenterol 2013;3(2):134-135.

Source of support: Nil

\section{Conflict of interest: None}

\section{INTRODUCTION}

Bone metastases from solid tumors are known to occur in thyroid, prostate, urinary bladder, breast, lung and kidney. ${ }^{1,2}$ Bone metastases from stomach cancer as the first site of dissemination is rare and occurs in 0 to $17 \%$. Symptoms of bony pain as first clinical feature is uncommon so is bone metastases. $^{3-5}$ We report a case of gastric carcinoma who presented with symptomatic bone metastases.

\section{CASE REPORT}

A 22-year-old male patient was admitted with back ache, loss of appetite and generalized weakness and anemia for 6 months. He had received 2 blood transfusion for anemia in a local hospital. On examination he was pale, no evidence of organomegaly, icterus and lymphadenopathy. Systemic examination was normal.

Blood investigations showed $\mathrm{Hb}$ of $5 \mathrm{gm} / \mathrm{dl}$, WBC count $4,000 / \mathrm{mm}^{3}$, platelets $80,000 / \mathrm{mm}^{3}$, alkaline phosphatase 2,400 $\mathrm{U} / 1$, LFT and renal function tests was normal. Peripheral smear was normocytic normochromic anemia. Endoscopy was done and no growth was found except for prominent mucosal folds (Fig. 1). Multiple biopsies from antrum and body were taken. Histopathology confirmed as well-differentiated adenocarcinoma of stomach (Figs 2 and 3). Computed tomography (CT) abdomen showed antral wall thickening of $3 \mathrm{~mm}$ (Fig. 4). CT thorax showed no evidence of metastases. Bone scintigraphy showed extensive skeletal metastases (Fig. 5). He received 6 cycles of chemotherapy (DCF regimen), and external beam radiotherapy for skeletal metastases. He was on regular follow-up on palliative treatment for pain and he succumbed after 3 months of diagnosis.

\section{DISCUSSION}

Bone metastases from gastric cancer as a first symptom is a rare. It is usually seen in advanced cancer and associated with

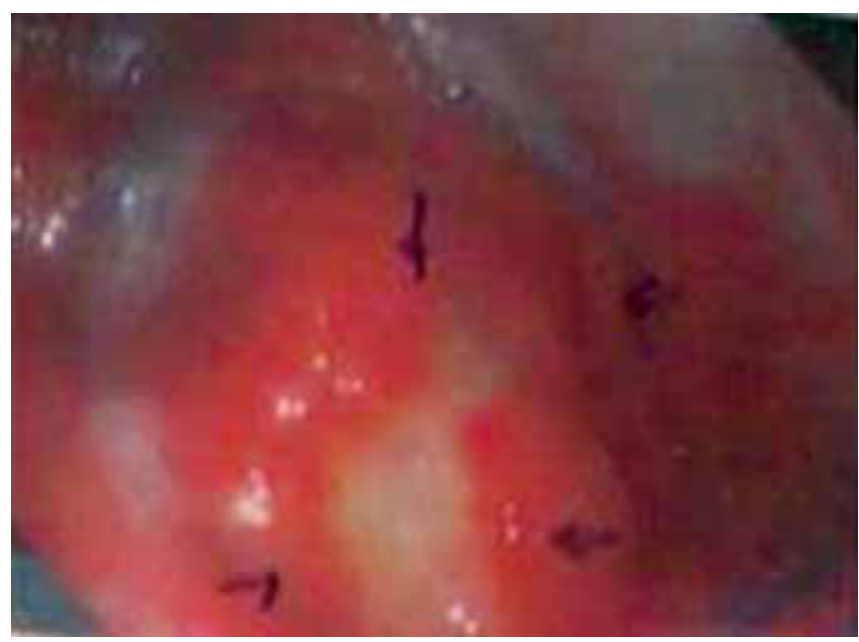

Fig. 1: Endoscopy photograph showing prominent gastric mucosal folds

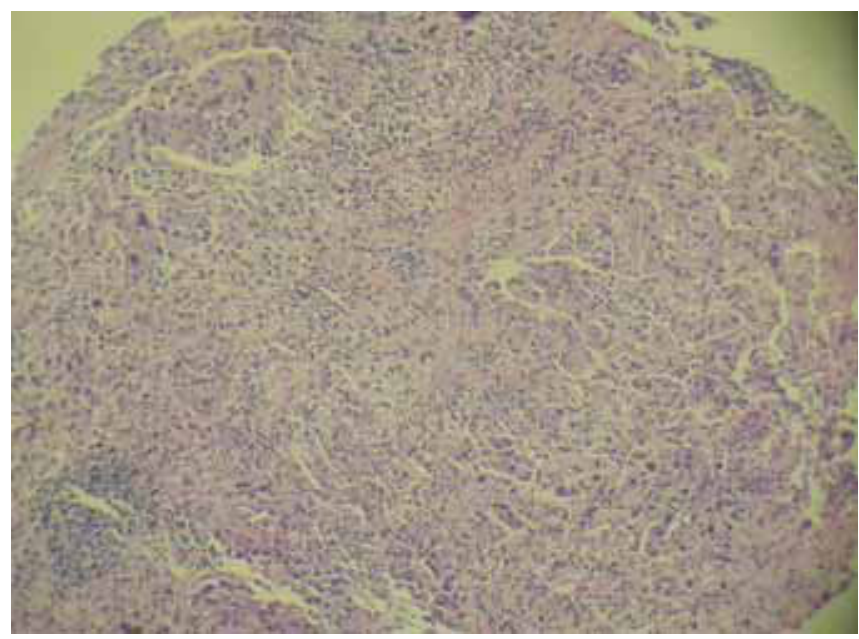

Fig. 2: Microphotograph showing moderately differentiated adenocarcinoma of stomach (H\&E 100x) 


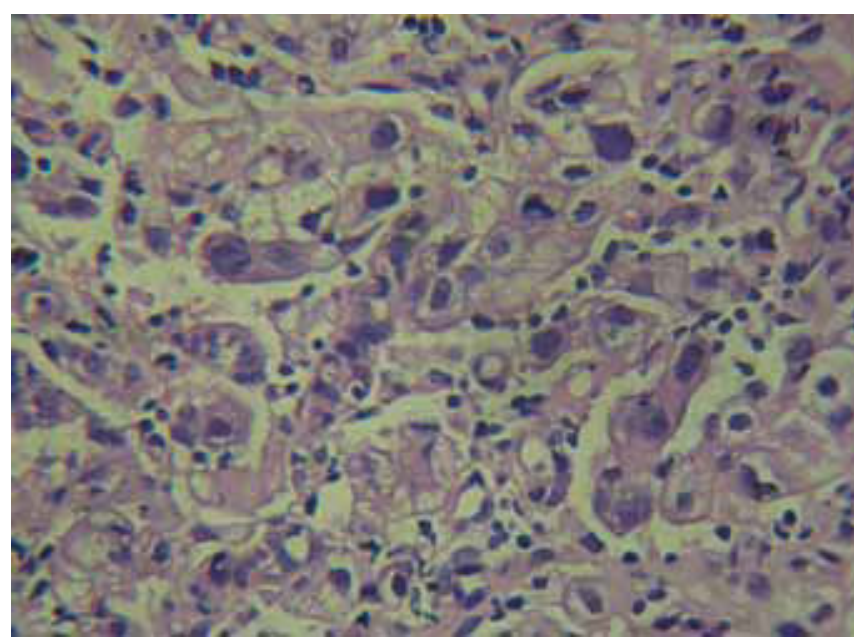

Fig. 3: Microphotograph showing tumor cells with hyperchromatic nuclei, moderately differentiated adenocarcinoma stomach (H\&E 400x)
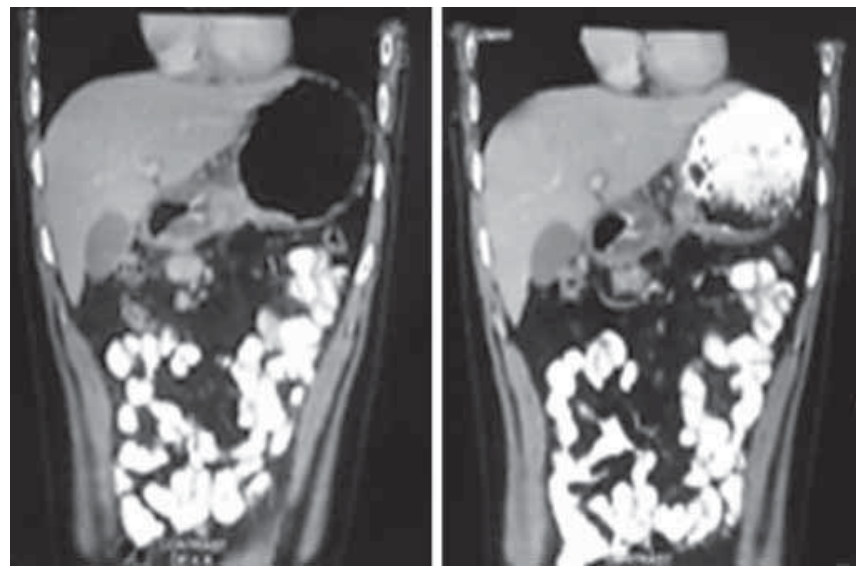

Fig. 4: CT scan abdomen (plain and contrast) showing antral wal thickening of $3.5 \mathrm{~cm}$

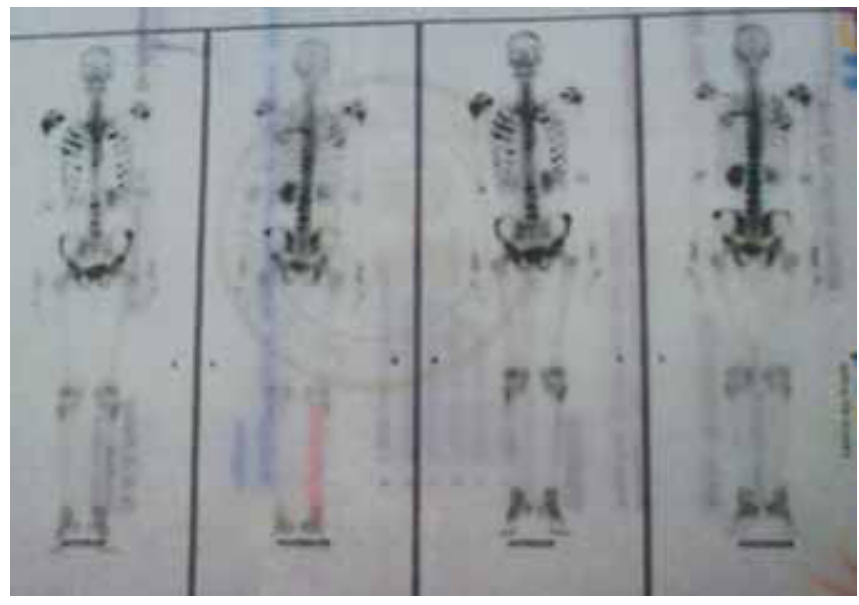

Fig. 5: Bone scan image showing extensive skeletal metastases

other sites of spread. In 1993, Mohandas et al reported four cases of gastric carcinoma presenting with bone metastases as an initial symptom. ${ }^{4}$ Borrman types III and IV, scirrhous carcinoma, and poorly differentiated adenocarcinomas of gastric cancer usually metastasis to bone. The early route of spread to bones is thought to be due to rich blood capillary network in the gastric mucosa as proposed by Lenhert et al. ${ }^{5,6}$ Absence of liver metastases is thought to be due to nonportal spread along vertebral plexus, transdiaphragmatic lower esophageal veins that bypass liver. Patients with bone metastases in gastric cancer have a poor survival rate of 2.5 to 5 months. $^{7}$

\section{CONCLUSION}

A thorough work up of the patients with anemia is mandatory to rule out hemolytic anemia, malignant conditions, such as gastric cancer with early bone metastases has to be considered.

\section{REFERENCES}

1. Mohandas KM, Swaroop VS, Krishnamurthy S, Desai DC, Dhir V, Pradhan SA, Jagannath P, Desouza LJ. Unusual bone metastases as the initial symptom of gastric cancer. A report of four cases. Indian J Cancer 1993 Sep;30(3):146-150.

2. Chung YS, Choi TY, Ha CY, Kim HM, Lee KJ, Park CH, Fitzpatrick LA. An unusual case of osteoblastic metastases from gastric carcinoma. Yonsei Med J 2002 Jan;43(3):577-580.

3. Lenhert T, Erlandson RA, DeCosse JJ. Lymph and blood capillaries of the gastric mucosa. A morphological basis for metastases in early gastric carcinoma. Gastroenterol 1985 Nov;89(5):939-950.

4. Arkenau HT, Mussig O, Buhr T, Jend HH, Porschen R. Microangiopathic hemolytic anemia (MAHA) as paraneoplastic syndrome in metastasized signet cell carcinoma: case reports and review of the literature. Z Gastroenterol 2005 Aug;43(8):719-722.

5. Sagara K, Fijiyama S, Kin F, Sato T. An unusual case of gastric carcinoma initially presenting with bone metastases and later transverse myelopathy. Jap J Clin Oncol 1985 Mar;15(1):133141.

6. Birla RK, Bowden L. Solitary bone metastasis as first sign of malignant tumor or its recurrence. Ann Surg 1975 Jul;182(1): 45-49.

7. Kamiyo T, Honda K, Kizaki M, Maruyama T, Masuda T, Suzuki O, Ookawa H, Kiryu Y, Takahashi S, Yasumura K, et al. Clinicopathological studies on disseminated carcinomatosis of the bone marrow occurring through metastasis of gastric carcinoma. Gan No Rinsho 1985 Jun;31(7):819-826.

\section{ABOUT THE AUTHORS}

\section{Ambikavathy Mohan (Corresponding Author)}

Associate Professor, Department of Surgery, Sri Devaraj Urs Medical College, Kolar, Karnataka, India, Phone: 9980337428 e-mail: ambikaashri67@live.com

\section{S Kumar}

Associate Professor, Department of Medicine, Sri Devaraj Urs Medical College, Kolar, Karnataka, India

\section{Bhaskaran Ashokan}

Professor, Department of Surgery, Sri Devaraj Urs Medical College Kolar, Karnataka, India 